\title{
Impaired endothelium-dependent and independent vasodilation in patients with Type 2 (non-insulin-dependent) diabetes mellitus
}

\author{
G. E. McVeigh ${ }^{1}$, G.M. Brennan ${ }^{1}$, G.D.Johnston ${ }^{1}$, B.J. McDermott ${ }^{1}$, L. T. McGrath ${ }^{1}$, W. R.Henry ${ }^{2}$, J. W. Andrews ${ }^{3}$ \\ and J.R.Hayes ${ }^{2}$
}

Department of Therapeutics and Pharmacology, The Queen's University of Belfast, ${ }^{2}$ Department of Medicine, Belfast City Hospital and
${ }^{3}$ Department of Medicine, Whiteabbey Hospital, Belfast, Northern Ireland

\begin{abstract}
Summary. The endothelium plays a pivotal role in modulating the reactivity of vascular smooth muscle through the formation of several vasoactive substances. We examined the effects of endothelium-dependent and independent vasodilators on forearm blood flow in 29 patients with Type 2 (noninsulin-dependent) diabetes mellitus and in 21 control subjects, using venous occlusion plethysmography. Via a brachial artery cannula, increasing amounts of acetylcholine and glyceryl trinitrate were infused in doses of $60,120,180$ and $240 \mathrm{mmol}$ per min and 3,6 and $9 \mathrm{nmol}$ per min respectively. $\mathrm{N}^{G}$ monomethyl-L-arginine, a stereospecific inhibitor of endothelium derived relaxing factor, was infused to inhibit basal and stimulated release of this dilator substance. Reactive hyperaemic forearm blood flow did not differ between groups. Forearm blood flow responses to each dose of acetylcholine were significantly greater in control than diabetic
\end{abstract}

subjects ( $p<0.01$ for all doses). $\mathrm{N}^{\sigma}$ monomethyl-L-arginine attenuated forearm blood flow from maximal stimulated values when responses were compared with the natural decline to acetylcholine in forearm flow in both control and diabetic subjects ( $p<0.05$ for both groups), but had no effect on basal blood flow responses. Forearm blood flow responses to each dose of glyceryl trinitrate were significantly greater in control than diabetic subjects ( $p<0.05$ for all). These data provide evidence for endothelial and smooth muscle dysfunction in diabetes which may have important therapeutic implications.

Key words: Acetylcholine, $\mathrm{N}^{\mathrm{G}}$ monomethyl-L-arginine, endothelium derived relaxing factor, glyceryl trinitrate, venous occlusion plethysmography, Type 2 (non-insulin-dependent) diabetes mellitus.
Accelerated atherosclerotic vascular disease is the principal cause of mortality in patients with Type 2 (non-insulindependent) diabetes mellitus [1]. The critical initiating event in the genesis of atherosclerosis may be endothelial injury with subsequent platelet adhesion and aggregation at the site of injury [2]. Evidence that endothelial dysfunction occurs in diabetes is shown by the finding of elevated plasma von Willebrand factor, impaired prostacyclin and plasminogen activator release and decreased lipoprotein lipase activity [3,4]. Although several conventional cardiovascular risk factors predisposing to endothelial damage including hyperglycaemia, hypertension and abnormalities in lipid and lipoprotein metabolism exist in these patients, they do not fully account for the marked increase in cardiovascular mortality [5].

The finding that the endothelium has an obligatory role in regulating vascular relaxation induced by acetylcholine through the liberation of endothelium derived relaxing factor (EDRF) [6], now identified as nitric oxide [7] or s-nitrosocysteine [8], has stimulated interest into its possible role in vascular disease [9]. Basal and stimulated re- lease of EDRF is important in regulating blood vessel tone and inhibiting platelet adhesion and aggregation, possibly protecting against vasospasm and thrombosis [910]. The impaired release of EDRF in response to pharmacological stimulation has been documented in patients with hypercholesterolaemia, atherosclerosis and hypertension [11-13], but has not been previously studied in vivo in Type 2 diabetic patients.

The aim of this study was to investigate endotheliumdependent and independent responses in the human forearm vasculature of patients with Type 2 diabetes.

\section{Patients and methods}

\section{Patients}

Twenty-four male and five female Type 2 diabetic patients of mean age 53 years (range 45-61 years) were recruited from the diabetic clinics at the Belfast City and Whiteabbey Hospitals. The known duration of diabetes was 5.2 years (range from 9 months to 16 years). Pa- 
Table 1. Characteristics of the study population

\begin{tabular}{|c|c|c|}
\hline Characteristic & Diabetic patients & Control subjects \\
\hline Sex (male/female) & $24 / 5$ & $16 / 5$ \\
\hline Age (years) & $\begin{array}{l}53 \\
\text { (range } 45 \text { to } 61 \text { ) }\end{array}$ & $\begin{array}{l}52 \\
\text { (range } 44 \text { to } 60 \text { ) }\end{array}$ \\
\hline Body mass index $\left(\mathrm{kg} / \mathrm{m}^{2}\right)$ & $26.6(24.8$ to 28.4$)$ & 25.3 (23.6 to 26.7$)$ \\
\hline $\begin{array}{l}\text { Total cholesterol } \\
(\mathrm{mmol} / \mathrm{h})^{\mathrm{a}}\end{array}$ & $5.5(5.1$ to 5.9$)$ & $5.5(5.1$ to 5.9$)$ \\
\hline $\begin{array}{l}\text { LDL cholesterol } \\
(\mathrm{mmol} / \mathrm{l})^{\mathrm{a}}\end{array}$ & $3.6(3.2$ to 4.0$)$ & $3.6(3.3$ to 3.9$)$ \\
\hline $\begin{array}{l}\text { Fasting blood glucose } \\
(\mathrm{mmol} / \mathrm{l})\end{array}$ & $\begin{array}{l}9.9 \\
\text { (range } 5.4 \text { to } 15.7 \text { ) }\end{array}$ & \\
\hline $\begin{array}{l}\text { Glycated haemoglobin } \\
(\%)\end{array}$ & $\begin{array}{l}9.7 \\
\text { (range } 6.3 \text { to } 12.9 \text { ) }\end{array}$ & \\
\hline
\end{tabular}

a To convert $\mathrm{mmol} / \mathrm{l}$ to $\mathrm{mg} / \mathrm{dl}$ multiply by 0.026 . Values expressed are mean and $95 \%$ confidence intervals unless stated. $p=$ NS for all comparisons with control values

tients had a mean fasting blood glucose concentration of $9.9 \mathrm{mmol} / \mathrm{l}$ (range 5.4-15.7). Diabetic control was achieved by diet alone or diet plus sulphonylurea or biguanide preparations or both. Sixteen male and five female healthy volunteers of mean age 52 years (range 44 60 years) and on no medication were recruited from the local community to act as a control group. All participants underwent a full medical history and physical examination. Subjects were excluded fromstudy if there was a history of cerebrovascular disease, ischaemic heart disease or peripheral vascular disease, hypertension (blood pressure $>150 / 90 \mathrm{mmHg}$ ), significant renal impairment (creatinine clearance $<30 \mathrm{ml} / \mathrm{min}$ ) or if they were taking any cardiovascular drugs (e.g. $\beta$-blockers, calcium antagonists). Clinical characteristics of all subjects recruited for study are shown on Table 1.

Each diabetic patient was carefully examined and assessed to grade the extent of end-organ involvement. Retinopathy was assessed by retinal photography. Each eye was dilated with cyclopentolate hydrochloride $1 \%$ and four overlapping $30^{\circ}$ horizontal fields were taken of each eye with a Zeiss fundus camera (Zeiss, Oberkochen,FRG) and Professional Kodachrome 25 film (Kodak, Hemel Hempstead, UK). Negatives were analysed by an ophthalmologist and graded using a system similar to recently modified proposals [14]. The retinopathy was assessed on a point-counting system and the features counted were microaneurysms and dot haemorrhages, hard exudates, blot and larger haemorrhages, cotton wool spots, laser lesions, intra-retinal microvascular abnormalities and new vessels.

Renal function was assessed by a 24-h urine collection to estimate creatinine clearance and urinary protein output. In addition two timed overnight samples were collected to estimate the prevalence of microalbuminuria in this group. This was measured by rate nephelometry using Beckman reagents [15]. Less than $20 \mu \mathrm{g}$ per min indicated normal urinary albumin excretion, 20-200 $\mu \mathrm{g}$ per min indicated incipient diabetic nephropathy and greater than $200 \mu \mathrm{g}$ per min indicated clinical diabetic nephropathy. Urine microscopy and culture were performed at these times to exclude a urinary tract infection.

Vibration perception was measured at the ankle and great toes using a biothesiometer. An age-adjusted value in an individual patient greater than the 95th centile, compared with values from a healthy population was regarded as abnormal [16]. Measurement of the variability in heart rate by electrocardiography during deep breathing was used to assess cardiac autonomic function. Changes in heart rate were compared with age-related normal ranges derived from previously published ranges from non-diabetic control subjects [17]. Heart rate responses below the 5th centile were taken as abnormal. Finally ankle/arm doppler pressure ratios were recorded to gauge the presence of occlusive vascular disease. A ratio of less than 0.9 confirmed significant vascular impairment.
All participants gave written informed consent for all procedures. This study was approved by the local ethical committee of the Queen's University of Belfast.

\section{Protocol}

Investigations were performed between 08.00 and 09.00 hours in a quiet temperature-controlled laboratory $\left(26-27^{\circ} \mathrm{C}\right)$ with the subjects lying supine. All participants fasted for $14 \mathrm{~h}$ prior to study. $\mathrm{Al}-$ cohol, caffeine and smoking were prohibited during this time. Under local anaesthesia (lignocaine $1 \%$ ) and sterile conditions, a 20-gauge polyethylene catheter (Vygon Leader Cath, Ecouen, France) was inserted into the brachial artery of each subject for the regional infusion of drugs and the recording of arterial blood pressure using a Bell and Howell pressure transducer aligned to an amplifier on an electromed physiologic recorder.

All subjects rested for 30 min after catheter placement to establish a stable baseline before data collection. $\mathrm{NaCl}(0.9 \%)$ was infused into the brachial artery at a rate of $0.3 \mathrm{ml} / \mathrm{min}$ during the control period. Forearm blood flow was measured bilaterally by venous occlusion plethysmography [18]. This well-established method of recording peripheral blood flow assesses variation in limb volume arising from alterations in blood flow at the level of the arteriolar resistance vessels. The forearms were rested comfortably on supports slightly above the level of the heart. Venous occlusion was achieved by blood pressure cuff applied proximal to the elbow and inflated to $40 \mathrm{mmHg}$ by a rapid cuff inflator. The hands were excluded from the circulation by inflating wrist cuffs to $200 \mathrm{mmHg}$ for $30 \mathrm{~s}$ before and during the blood flow measurements. In order to detect variations in limb volume, indium/gallium strain gauges were placed around the widest part of the forearm and were coupled to an electronically calibrated plethysmograph (Medasonics Model SPG16; Medasonics, Mountain View, Calif. USA) connected to a two-channel chart recorder (Medasonics Model R12B) which recorded the forearm flow measurements. Each forearm blood flow determination comprised five separate measurements performed at $10-15$ sintervals. Drug infusions were performed in the experimental forearm to determine the direct effect of the vasoactive drug, while the forearm flow measurements in the control arm were monitored to ensure that systemic effects did not occur during this period. The mean values of the five consecutive forearm flow measurements were taken for statistical evaluation. Forearm vascular resistance was calculated as the ratio of mean blood pressure to forearm blood flow.

The circulatory response to reactive hyperaemia induced by temporary cessation ( $5 \mathrm{~min}$ ) of forearm blood flow by inflation of a sphygmomanometer cuff on the upper arm to suprasystolic pressure was recorded in 21 diabetic and 13 control subjects. Forearm blood flow measurements were repeated in these subjects until basal conditions were re-established.

To assess endothelium-dependent vasodilation acetylcholine chloride (Miochol; Coopervision, Southampton, UK) was administered via the brachial artery. Acetylcholine chloride $20 \mathrm{mg}$ and mannitol $60 \mathrm{mg}$ were dissolved in $2 \mathrm{ml}$ of water for injection to obtain a 1:100 solution of acetylcholine chloride in $3 \%$ mannitol. Serial dilutions were made from the stock solution and administered within 90 min of reconstitution.

$\mathrm{N}^{\mathrm{G}}$-monomethyl-L-arginine (L-NMMA), (Ultrafine Chemicals, Manchester, UK) was dissolved in $50 \mathrm{ml}$ of sterile physiological saline. Prior to administration the solution was filter sterilised through a $0.2 \mu \mathrm{m}$ disposable filter (Millipore, Boston, Mass., USA). Suitable aliquots were stored under vacuum at $-70^{\circ} \mathrm{C}$ and thawed immediately before use within a 3-week period.

Forearm blood flow was recorded after 3 -min infusions of acetylcholine administered at $1 \mathrm{ml} / \mathrm{min}$ via Braun perfusor VI infusion pump at increasing doses of $60,120,180$ and $240 \mathrm{nmol} / \mathrm{min}$. In a group of nine diabetic and six control subjects forearm blood flow measurements were recorded at $2,4,6,8,10,15,20,25$ and 30 min after the maximum dose of acetylcholine infused to evaluate the time course of the vasodilator response to this agent. On achieving 
Table 2. Resting forearm blood flow

\begin{tabular}{lll}
\hline & Diabetic patients & Control subjects \\
\hline Before acetycholine & $3.3(2.7$ to 3.9$)$ & $3.9(3.3$ to 4.5$)$ \\
Before L-NMMA & $3.1(2.0$ to 4.2$)$ & $3.5(2.0$ to 5.0$)$ \\
Before glyceryl trinitrate & $3.1(2.5$ to 3.7$)$ & $3.3(2.7$ to 3.9$)$ \\
\hline
\end{tabular}

Units are $\mathrm{ml} \cdot 100 \mathrm{ml}^{-1} \cdot \mathrm{min}^{-1}$. Values expressed are mean and $95 \%$ confidence intervals. $p=\mathrm{NS}$ for comparisons with control values. L-NMMA, $\mathrm{N}^{G}$ monomethyl-L-arginine

basal blood flow the infusions were repeated once again in these subjects to give reproducible vasodilation. Immediately after recording the blood flow response to the maximum dose of acetylcholine, L-NMMA was infused at a dose of $2 \mu \mathrm{mol} / \mathrm{min}$ for $5 \mathrm{~min}$. Forearm blood flow measurements were then recorded after $1,3,5$, 10 and $20 \mathrm{~min}$ to assess the effect of the arginine analogue on the natural decline in blood flow to the acetylcholine infusions. On attainment of basal blood flow L-NMMA was again infused in all subjects at a concentration of $2 \mu \mathrm{mol} / \mathrm{min}$ for $5 \mathrm{~min}$ to determine the contribution of basal release of EDRF in maintaining forearm blood flow. Forearm flow measurements were recorded at 1 and 5 min on completion of the infusion.

Glyceryl trinitrate (Nitrocine Schwarz Pharma, Chesham, UK) was then infused to study the responsiveness of the arterial smooth muscle in increasing doses of 3,6 and $9 \mathrm{nmol} / \mathrm{min}$ at $1 \mathrm{ml} / \mathrm{min}$. Forearm blood flow measurements were recorded on completion of each 3-min infusion period. All forearm blood flow calculations were performed by an independent investigator (GDJ) blinded to the study protocol.

Venous blood was withdrawn from each subject after $30 \mathrm{~min}$ supine rest for estimation of glycated haemoglobin and fasting glucose by standard techniques. An uncuffed specimen was collected in EDTA tubes for estimation of the lipid and lipoprotein profiles by ultracentrifugation.

\section{Statistical analysis}

Forearm vasodilator responses to increasing doses of acetylcholine and glyceryl trinitrate in control and diabetic subjects were analysed using the SPSS PC+ package (SPSS Inc, Chicago, Ill., USA). Repeated measures analysis of variance was used to assess withingroup analysis and between-group responses for significant comparisons between doses. Multiple comparisons with baseline values in each group were performed using Dunnett's test. Comparisons between groups were assessed using unpaired $t$-tests. For regression analysis, forearm vasodilator response was calculated as maximum stimulated flow minus baseline flow and this variable was transformed to $\log _{e}(1+x)$ to normalise the skewed distribution. Correlations between response and metabolic control and physical complications in diabetic subjects were sought using multiple regression analysis. All data are reported as mean values and $95 \%$ confidence intervals (CI) unless otherwise stated.

\section{Results}

The baseline characteristics of the normal control subjects and the diabetic patients were similar. No differences were found in age, body mass index, plasma cholesterol and low density lipoprotein levels (Table 1) or in resting forearm blood flow prior to administration of acetylcholine, L-NMMA and glyceryl trinitrate (Table 2).

Baseline blood flow in the 13 control and 21 diabetic subjects who underwent reactive hyperaemic responses were similar (Fig. 1). Reactive hyperaemic blood flow af- ter a 5-min ischaemic period in control subjects was not different from that in diabetic patients.

Mean arterial blood pressure and heart rate at baseline were not different between control and diabetic subjects mean 84.5 (CI: 78.1 to 90.9 ) and mean 83.7 (CI: 79.4 to $88.0)$ for arterial pressure and mean 65 (CI: 60 to 70 ) and mean 68 (CI: 64 to 72) for heart rate, respectively (NS for both). The incremental intra-arterial infusions of acetylcholine produced no changes in systemic blood pressure, heart rate or altered forearm blood flow in the non-infused arm in either control or diabetic subjects.

The infusions of acetylcholine significantly increased forearm blood flow in control and diabetic subjects from baseline, although the magnitude of change was markedly different between groups as illustrated in Figure 2. At all doses of acetylcholine infused control subjects had a significantly greater increase in forearm blood flow than diabetic patients. These changes in forearm blood flow to acetylcholine reflect changes in forearm vascular resistance as blood pressure did not change in either group.

Sulphonylurea preparations may block the vasodilation to acetylcholine by inhibiting the effects of an endothelium-derived hyperpolarising factor on the vascular smooth muscle [19]. The vasodilator response to acetyl-

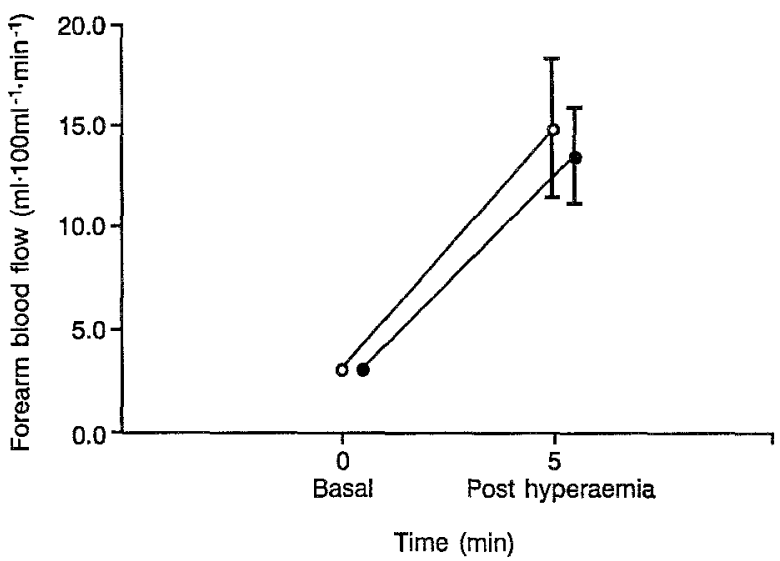

Fig. 1. Forearm blood flow at baseline and after $5 \mathrm{~min}$ ischaemia in 13 control (O) and 21 diabetic ( $)$ subjects, mean and $95 \%$ confidence intervals

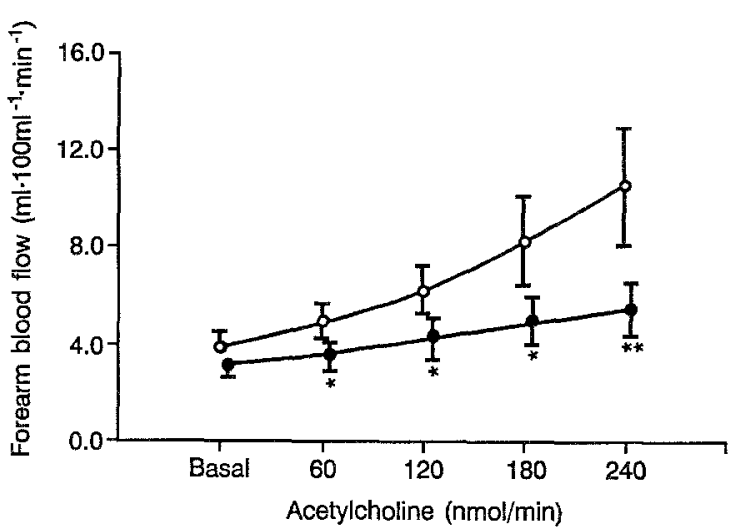

Fig.2. Forearm blood flow response to the incremental intra-arterial infusion of acetylcholine in 21 control $(O)$ and 29 diabetic $(\bullet)$ subjects, mean and $95 \%$ confidence intervals. ${ }^{*} p<0.01,{ }^{* * *} p<0.001$ 


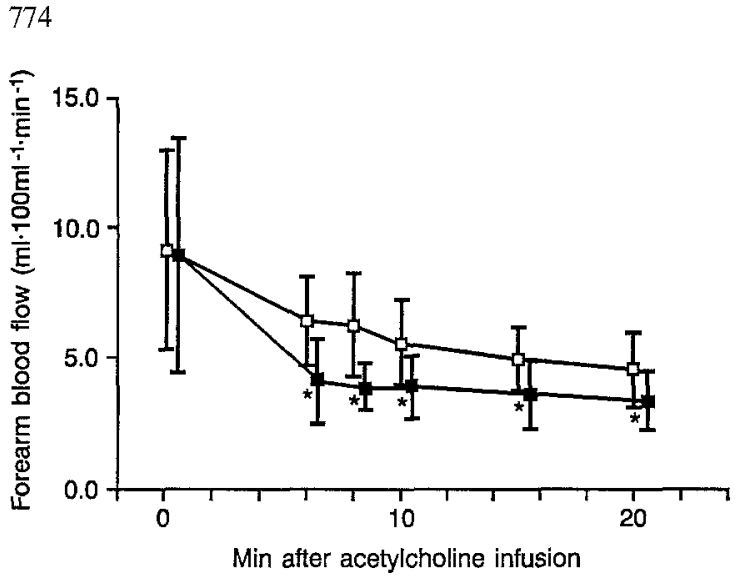

Fig. 3. Decline in forearm blood flow in nine diabetic subjects from maximal stimulated flow to the incremental intra-arterial infusion of acetylcholine. Decline in forearm blood flow with $\mathrm{N}^{\mathrm{G}}$ monomethylL-arginine (L-NMMA) ( $\square$ ). Decline in forearm blood flow on completion of a $5-\mathrm{min}$ infusion of L-NMMA at $2 \mu \mathrm{mol} / \mathrm{min}(\boldsymbol{\sigma})$, mean and $95 \%$ confidence intervals. ${ }^{*} p<0.01$

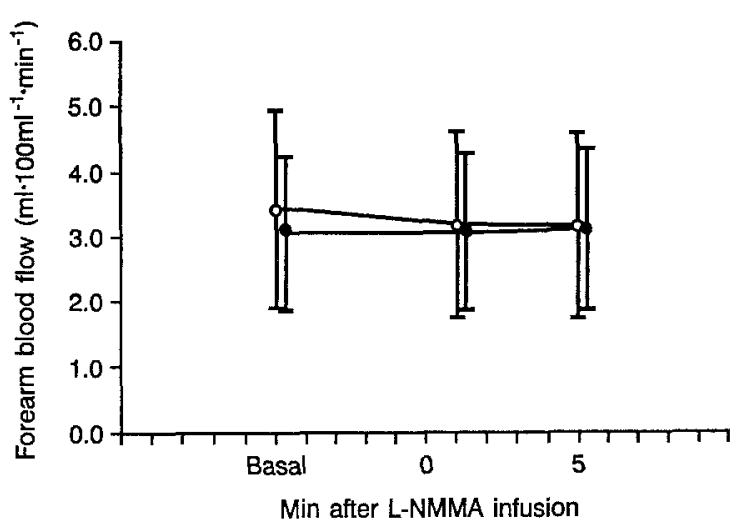

Fig.4. Effect of $\mathrm{N}^{G}$ monomethyl-L-arginine (L-NMMA) infused at $2 \mu \mathrm{mol} / \mathrm{min}$ for $5 \mathrm{~min}$ on basal forearm blood flow after 1 and $5 \mathrm{~min}$ in 21 control ( $O$ ) and 29 diabetic ( $)$ subjects, mean and $95 \%$ confidence intervals. $p=\mathrm{NS}$

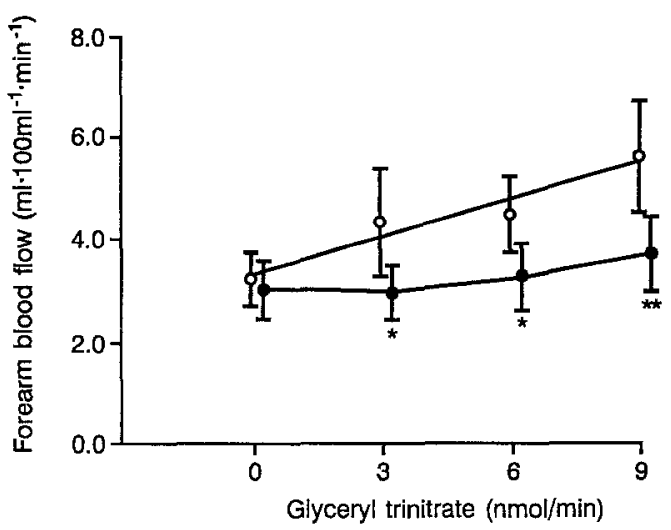

Fig.5. Forearm blood flow response to the incremental intra-arterial infusion of glyceryl trinitrate in 21 control $(O)$ and 29 diabetic (๑) subjects, mean and $95 \%$ confidence intervals. ${ }^{*} p<0.05$, *** $p<0.01$

choline in diabetic subjects on sulphonylurea drugs (11 patients) was compared with those controlled by diet alone (12 patients). No differences in forearm blood flow
G.E.McVeigh et al.: Arterial responses in Type 2 diabetes mellitus

response to acetylcholine were observed between groups $(t=1.27, p=0.22)$.

In a sub-group of nine diabetic and in six control subjects the time course of the decline in forearm blood flow from the maximal stimulated values produced by acetylcholine was recorded. On attainment of basal blood flow the incremental infusions of acetylcholine were repeated. On completion of the second dose response curve, L-NMMA was infused in a concentration of $2 \mu \mathrm{mol} / \mathrm{min}$ for $5 \mathrm{~min}$, and the forearm blood flow responses were again recorded in each group. As illustrated in Figure 3, L-NMMA produced significant decrements in forearm blood flow when compared with the uninhibited decline in forearm blood flow in diabetic subjects. Very similar changes were also observed in control subjects (data not shown).

In all subjects the effect of L-NMMA infused in a concentration of $2 \mu \mathrm{mol} / \mathrm{min}$ for $5 \mathrm{~min}$ on basal blood flow was examined. As shown in Figure 4, L-NMMA did not alter basal forearm blood flow responses either in diabetic or control subjects.

The infusions of glyceryl trinitrate produced no changes in mean arterial pressure, heart rate or in forearm blood flow in the non-infused arm in either control or diabetic subjects.

Maximal stimulated forearm blood flow produced by glyceryl trinitrate was not different from baseline values in diabetic subjects, and contrasted with the effects recorded in control subjects where a significant increase in forearm blood flow from baseline occurred with each dose. The effect of glyceryl trinitrate on forearm blood flow was significantly greater in control than in diabetic subjects at each dose infused as shown in Figure 5.

In the diabetic population 12 patients had retinopathy, 7 had evidence of cardiac vagal denervation, 4 had abnormal ankle/arm doppler ratios, 3 had evidence of microalbuminuria and 2 had impaired ankle vibration perception. No correlations were found between the presence of one or more complications and the vascular response to vasoactive drugs. Neither were any significant correlations found between the known duration of diabetes, fasting glucose, glycated haemoglobin and low density lipoprotein cholesterol with forearm blood flow response to acetylcholine or glyceryl trinitrate. No direct association was found between forearm blood flow responses to acetylcholine and glyceryl trinitrate in the diabetic population $(r=0.30, p=0.11)$.

\section{Discussion}

The principal findings of this study provide evidence for impaired endothelium-dependent and endothelium-independent vasoactive responses to acetylcholine and glyceryl trinitrate respectively, in the forearm vasculature of patients with Type 2 diabetes.

EDRF generated by the action of acetylcholine on muscarinic receptors on endothelial cells appears to be nitric oxide or an unstable nitroso compound related to nitric oxide [8]. Endothelial cells synthesise EDRF from the terminal guanidino nitrogen of L-arginine [20]. This process can be inhibited stereospecifically by the arginine analogue 
L-NMMA. Thus, L-NMMA will specifically inhibit endothelium-dependent vasodilation produced by EDRF without affecting endothelium-independent vasodilation produced by exogenous nitrovasodilators [21-23].

Reactive hyperaemic blood flow responses were similar between groups suggesting that structural changes in the forearm arteriolar resistance vessels did not play an important role in attenuating vasoactive responses in diabetic patients [24]. By contrast the vasodilator responses to acetylcholine were markedly impaired in diabetic patients compared with control subjects. In the sub-group of diabetic patients who vasodilated to the acetylcholine infusions the natural decline in forearm blood flow was monitored until basal conditions were re-established. L-NMMA was then infused immediately on completion of a second set of acetylcholine infusions which resulted in reproducible vasodilation and significantly attenuated the decline in forearm blood flow when compared with the uninhibited natural decline in flow. These data further emphasise the contribution made by EDRF in producing vasodilation to acetylcholine. Vallance et al. [23] demonstrated that pre-treatment with L-NMMA at doses of $4 \mu \mathrm{mol} / \mathrm{min}$ for $5 \mathrm{~min}$ inhibited the forearm blood flow response to acetylcholine in healthy volunteers. However, infusion of the arginine analogue decreased basal blood flow and altered vascular tone, making comparisons of the dose response curves difficult. We found L-NMMA, although capable of inhibiting stimulated flow when infused at a dose of $2 \mu \mathrm{mol} / \mathrm{min}$ for $5 \mathrm{~min}$, was unable to influence basal blood flow in a consistent manner in either control subjects or diabetic patients. The discrepancy in these results does not necessarily suggest an absence of basal EDRF secretion but may reflect both the lower dose of L-NMMA administered, and also the greater age of our control group compared with those previously studied, as ageing alone has been shown to impair vasodilator responses to acetylcholine [25].

The blunted vasodilator responses to acetylcholine in diabetic patients suggests diminished production or release of EDRF and represents a further marker of endothelial cell dysfunction in Type 2 diabetes. Sub-clinical atherosclerosis in the forearm vessels could have contributed to the impaired responses observed in diabetic subjects, and cannot be completely excluded as a confounding variable. However, plethysmographic measurement of forearm blood flow reflects changes at the level of the arteriolar resistance vessels that do not develop atheromatous plaques [12]. Vasodilation may also have been offset by the simultaneous secretion of a vasoconstrictor substance. This possibility appears unlikely as blood flow would be expected to decrease below baseline after inhibition of EDRF secretion by L-NMMA on completion of the acetylcholine infusions.

Membrane hyperpolarisation produced by an endogenous endothelium-derived hyperpolarising factor is known to contribute to the endothelium-dependent relaxation of vascular smooth muscle in response to acetylcholine. Oral sulphonylurea drugs may antagonise the vasodilator actions of this agent by blocking smooth muscle potassium channels opened by the endothelium-derived hyperpolarising factor [19]. No difference was found in the forearm vasodilator response in diabetic patients controlled on diet only and those controlled on diet and sulphonylureas, indicating these drugs had no significant effect in blunting the forearm blood flow response to acetylcholine.

The reduced responsiveness of the arterial smooth muscle to glyceryl trinitrate was an unexpected finding and has not been reported previously in diabetic subjects. Recently Bucala et al. [26] have reported defective vasodilation in experimental diabetes to nitric oxide and glyceryl trinitrate. The blunted vasodilator response to glyceryl trinitrate suggests that dysfunctional endothelium is not solely responsible for the impaired vascular relaxation observed in diabetic patients. As glyceryl trinitrate and EDRF share a common final pathway to produce vasodilation [27], a selective functional defect in the diabetic vasculature could account for the impaired responses to these nitrovasodilators. However, no correlation was found between the vasodilator responses to acetylcholine and glyceryl trinitrate in individual diabetic subjects, suggesting multiple mechanisms are involved in impairing vascular responses to these drugs.

No correlation was observed between a blunted forearm vasodilator response to acetylcholine and glyceryl trinitrate and known duration of diabetes, low density lipoprotein cholesterol, fasting glucose and glycated haemoglobin levels. The presence of a physical complication of the disease did not predict an impaired dilator response to the vasoactive drugs, although with the small numbers involved a beta type two error cannot be excluded.

Altered vascular responses in the forearm arterial bed of diabetic subjects are particularly striking as this circulation is often spared complications of the disease. More pronounced damage is known to occur in the coronary, renal, cerebral and lower limb circulations. For example in diabetic patients the incidence of coronary heart disease is increased two- to four-fold and responsible for $50-60 \%$ of adult deaths [28]. The results of this study suggest that diabetic patients may not only lack a protective mechanism that guards against vasospasm and thrombosis but may not respond normally to a therapeutic agent used routinely to treat ischaemic heart disease.

In conclusion, impaired vasodilator responses were demonstrated in the forearm arterial bed to acetylcholine and glyceryl trinitrate in patients with Type 2 diabetes. Further studies are necessary to elucidate the mechanisms involved in producing the impaired responses to exogenous and endogenous nitrovasodilators in the diabetic vasculature.

Acknowledgements. This work has been supported by a grant from the British Diabetic Association. Dr. Brennan is a Research Fellow supported by the British Diabetic Association.

\section{References}

1. Ganda OP (1980) Pathogenesis of macrovascular disease in the human diabetic. Diabetes 29: 931-942

2. Colwell JA, Lopes-Virella M, Halushka PV (1981) Pathogenesis of atherosclerosis in diabetes mellitus. Diabetes Care 4: 121-133 
3. Ruderman NB, Haudenschild C (1984) Diabetes as an atherogenic factor. Prog Cardiovasc Dis 26: 373-412

4. Steiner G (1981) Diabetes and atherosclerosis. Diabetes 30 [Suppl 2]: 1-7

5. Jensen T, Feldt-Rasmussen B, Bjerre-Knudsen J, Deckert T (1989) Features of endothelial dysfunction in early diabetic nephropathy. Lancet II: 461-463

6. Furchgott RF, Zawadzki JV (1980) The obligatory role of endothelial cells in the relaxation of arterial smooth muscle by acetylcholine. Nature 288: 373-376

7. Palmer RMJ, Ferrige AG, Moncada S (1987) Nitric oxide release accounts for the biological activity of endothelium-derived relaxing factor. Nature 327:524-526

8. Myers PR, Minor RL Jr, Guerra R Jr, Bates JN, Harrison DG (1990) Vasorelaxant properties of the endothelium-derived relaxing factor more closely resemble s-nitrosocysteine than nitric oxide. Nature 345: 161-163

9. Griffith TM, Lewis MJ, Newby AC, Henderson AH (1988) Endothelium-derived relaxing factor. J Am Coll Cardiol 12: 797-806

10. Vane JR, Anggard EE, Botting RM (1990) Regulatory functions of the vascular endothelium. N Engl J Med 323:27-36

11. Panza JA, Quyyumi AA, Brush JE Jr, Epstein SE (1990) Abnormal endothelium-dependent vascular relaxation in patients with essential hypertension. N Engl J Med 323: 22-27

12. Creager MA, Cooke JP, Mendelsohn ME et al. (1990) Impaired vasodilation of forearm resistance vessels in hypercholesterolemic humans. J Clin Invest 86: 228-234

13. Cohen RA, Zitnay KM, Haudenschild CL, Cunningham LD (1988) Loss of selective endothelial cell vasoactive functions caused by hypercholesterolemia in pig coronary arteries. Circ Res 63: 903-910

14. Davis MD, Hubbard LD, Trautman J, Klein R (1985) Studies of retinopathy. Methodology for assessment and classification with fundus photographs. Diabetes 34 [Suppl 3]: 42-49

15. Sternberg JC (1977) A rate nephelometer for measuring specific proteins by immunoprecipitin reactions. Clin Chem 23: 14561464

16. Bloom S, Till S, Sönksen P, Smith S (1984) Use of a biothesiometer to measure vibration thresholds and their variation in 519 non-diabetic subjects. BMJ 288: 1793-1795

17. O'Brien IAD, O'Hare JP, Lewin IG, Corrall RJM (1986) The prevalence of autonomic neuropathy in insulin-dependent diabetes mellitus: a controlled study based on heart rate variability. Quart J Med 61:957-967

18. Whitney RJ (1953) The measurement of volume changes in human limbs. J Physiol (Lond) 121: 1-27
19. Edwards G, Weston AH (1990) Potassium channel openers and vascular smooth muscle relaxation. Pharmac Ther 48:237-258

20. Palmer RMJ, Ashton DS, Moncada S (1988) Vascular endothelial cells synthesize nitric oxide from L-arginine. Nature 333: 664 666

21. Rees DD, Palmer RMJ, Moncada S (1989) Role of endotheliumderived nitric oxide in the regulation of blood pressure. Proc Natl Acad Sci 86: 3375-3378

22. Johns RA, Peach MJ, Linden J, Tichotsky A (1990) $\mathrm{N}^{\mathrm{G}}$ monomethyl $\mathrm{L}$-arginine inhibits endothelium-derived relaxing factorstimulated cyclic GMP accumulation in cocultures of endothelial and vascular smooth muscle cells by an action specific to the endothelial cell. Circ Res 67:979-985

23. Vallance P, Collier J, Moncada S (1989) Effects of endotheliumderived nitric oxide on peripheral arteriolar tone in man. Lancet II: $997-1000$

24. Paterson GC, Whelan RF (1955) Reactive hyperaemia in the human forearm. Clin Sci 14: 197-211

25. Yasue $\mathbf{H}$, Matsuyama K, Matsuyama K, Okumara K, Morikami Y, Ogawa H (1990) Responses of angiographically normal human coronary arteries to intracoronary injection of acetylcholine by age and segment. Circulation 81: $482-490$

26. Bucala R, Tracey KJ, Cerami A (1991) Advanced glycosylation products quench nitric oxide and mediate defective endothelium-dependent vasodilation in experimental diabetes. J Clin Invest $87: 432-438$

27. Ignarro LJ (1989) Biological actions and properties of endothelium-derived nitric oxide formed and released from artery and vein. Circ Res 65: 1-21

28. Colwell JA, Lopes-Virella MF (1988) A review of the development of large vessel disease in diabetes mellitus. Am J Med 28: 113-118

Received: 10 February 1992

and in revised form: 21 April 1992

Dr. G.E.McVeigh

Department of Therapeutics and Pharmacology

The Queen's University of Belfast

The Whitla Medical Building

97 Lisburn Road

Belfast BT9 7BL

Northern Ireland 